\title{
Tularaemia seroprevalence of captured and wild animals in Germany: the fox (Vulpes vulpes) as a biological indicator
}

\author{
A. KUEHN ${ }^{1,2}$, C. SCHULZE ${ }^{3}$, P. KUTZER ${ }^{3}$, C. PROBST ${ }^{4}$, A. HLINAK ${ }^{3}$, A. OCHS ${ }^{5}$ \\ AND R. GRUNOW ${ }^{1 *}$ \\ ${ }^{1}$ Robert Koch-Institut, Centre for Biological Security 2, Berlin, Germany \\ ${ }^{2}$ Helmholtz Zentrum Muenchen, Research Unit of Molecular Epidemiology, Neuherberg, Germany \\ ${ }^{3}$ Landeslabor Berlin-Brandenburg, Frankfurt (Oder), Germany \\ ${ }^{4}$ Friedrich-Loeffler-Institute, Institute of Epidemiology, Wusterhausen, Germany \\ ${ }^{5}$ Zoo Berlin AG, Berlin, Germany
}

Received 29 November 2011; Final revision 21 March 2012; Accepted 26 April 2012; first published online 17 July 2012

\section{SUMMARY}

A total of 2475 animals from Germany, both captive and wild, were tested for antibodies against Francisella tularensis to obtain more knowledge about the presence of this pathogen in Germany. An indirect and a competitive ELISA served as screening methods, positive and inconclusive samples were confirmed by Western blot. Of the zoo animals sampled between 1992 and 2007 $(n=1122)$, three $(0 \cdot 3 \%)$ were seropositive. The seroconversion of a hippopotamus in Berlin Zoo was documented. From 1353 serum samples of wild foxes (Vulpes vulpes), raccoon dogs (Nyctereutes procyonoides) and wild boars (Sus scrofa), collected between 2005 and 2009 in the federal state of Brandenburg (surrounding Berlin), a total of 101 (7.5\%) tested positive for antibodies to $F$. tularensis lipopolysaccharide. Our results indicate a higher seroprevalence of F. tularensis in wildlife in eastern Germany than commonly assumed. Furthermore, we found foxes and raccoon dogs to be biological indicators for tularaemia.

Key words: Serology, zoonoses.

\section{INTRODUCTION}

Tularaemia is a zoonosis caused by the Gram-negative, pleomorphic, non-motile bacterium Francisella tularensis, capable of growing intracellularly. Because of its high infectivity and low infectious dose, F. tularensis has been classified as a potential bioterrorism agent [1]. The species $F$. tularensis includes two clinically relevant subspecies: tularensis and holarctica which

\footnotetext{
* Author for correspondence: PD Dr. R. Grunow, Centre for Biological Security 2, Robert Koch-Institut, Nordufer 20, D-13353 Berlin, Germany.

(Email: GrunowR@rki.de)
}

differ in virulence and geographical distribution [2]. In Europe, the subspecies most frequently detected is holarctica and various endemic regions have been identified [3]. The subspecies remain phylogenetically closely related and antigenically almost similar [4]. Tularaemia has been reported in a broad range of animal species with varying susceptibility [2, 5], while arthropods and ticks serve as vectors [2, 6]. Humans often acquire an infection by handling animal skins or carcasses, drinking contaminated water or eating uncooked meat from infected animals [7]. Lagomorphs (hares and rabbits), various rodents (e.g. muskrats, voles, mice, lemmings, and hamsters) and insectivores 
(e.g. shrews and moles) are the animals most susceptible and can also serve as $F$. tularensis reservoirs $[2,5]$. Canidae and Felidae are probably resistant to the pathogen. In regions where tularaemia is endemic antibodies against $F$. tularensis can be detected in sera from wild animals [8], and frequently outbreaks of the disease occur simultaneously in wild animals and humans $[6,9]$.

In Germany, human infections caused by $F$. tularensis are rare but distributed throughout the country, with some historical as well as recent 'hot spots' $[10,11]$. Although tularaemia is a reportable disease in Germany, it can be assumed that many cases have not been recognized due to a mild course of the disease or failure to consider it as a differential diagnoses. The natural occurence of $F$. tularensis in Germany has not been well studied, thus, the reservoirs and transmission routes of the pathogen are largely unknown. Finally, due to the paucity of evidence-based information the risk for human tularaemia is difficult to predict.

Seroprevalence studies in various animal populations could help to estimate the occurrence of the tularaemia pathogen in nature. Two previous studies in the north of Germany revealed the absence of F. tularensis antibodies in hares [12] but a seroprevalence of $3.5 \%$ in wild boars [13]. For the present study we used the standard methods, i.e. competitive or indirect enzyme-linked immunosorbent assay (ELISA) and Western blot (WB), for the detection of $F$. tularensis antibodies showing reactivity with the lipopolysaccharide (LPS) of the bacterium. The LPS of this pathogen is highly specific and represents the main target for species-specific antibodies [14]. In previous studies it has been shown that these antibodies did not recognize LPS of potentially crossreacting bacteria [15]. The aim of this study was to obtain more information about the prevalence of F. tularensis in the federal state of Brandenburg, a geographical region in Germany that has not been well studied and to investigate the tularaemia seroprevalence in zoo animals because this has not been investigated previously in Germany. The expected data could show the exposition of the studied animal populations to $F$. tularensis and could be helpful in estimating the potential risk for transmission of tularaemia from animals to humans and between animal populations. Zoo animals are of interest to study because they could have contacts with wild animals including tularaemia-transmitting species. The investigation of carnivores and omnivores could serve as indicators for a broader spectrum of wild animal species highly susceptible and sensitive to the causative agent of tularaemia, thereby simplifying the monitoring of wild life.

\section{MATERIALS AND METHODS}

\section{Study sites}

Blood from wild animals was collected in the federal state of Brandenburg which is located in the northeast of Germany (Fig. 1a, green area). Moreover, serum samples from zoo animals that had been collected between 1992 and 2007 for a serosurvey in central European zoos [16] were analysed. They originated from 11 zoological gardens in Germany (Fig. 1a, red numbers): 1, Berlin Zoological Park Friedrichsfelde; 2, Berlin Zoo; 3, Dortmund Zoo; 4, Gelsenkirchen Zoo; 5, Hagenbeck Zoological Park (Hamburg); 6, Hanover Zoo; 7, Karlsruhe Zoo; 8, Krefeld Zoo; 9, Leipzig Zoo; 10, Nuremberg Zoological Park; 11, Stuttgart Wilhelma Zoological and Botanical Garden.

\section{Data and sample collection}

A total of 1122 serum samples from 1122 animals, comprising mainly ungulates, were collected in the zoos and zoological parks (serum collection 1). They represented 73 species of Bovidae, 20 species of Cervidae, 14 species of Equidae, nine species of Camelidae, two species of Caviidae and one species each of Giraffidae, Suidae and Rhinocerotidae, respectively. Berlin Zoo provided serum samples taken from a broad range of animal species, comprising Elephantidae, primates, Rhinocerotidae, Ursidae, Felidae, birds, Hippopotamidae and Tapiridae, representing a total of 46 different species. All sera from zoo animals were summarized in two groups ungulates and other species (Table 1). Blood samples were collected during immobilization for routine clinical treatment (worming, vaccination) or transport. Only clinically healthy animals were tested. The sample set was assembled from archival blood collected by zoo veterinarians between 1992 and 2007. After centrifugation for $10 \mathrm{~min}$ at $3000 \mathrm{rpm}$, serum samples were stored at $-20{ }^{\circ} \mathrm{C}$ until testing.

A total of 1353 serum samples (serum collection 2) from 928 wild foxes (Vulpes vulpes) (69\% of total number), 345 wild raccoon dogs (Nyctereutes procyonoides) $(25 \%)$ and 80 wild boars (Sus scrofa) $(6 \%)$ 


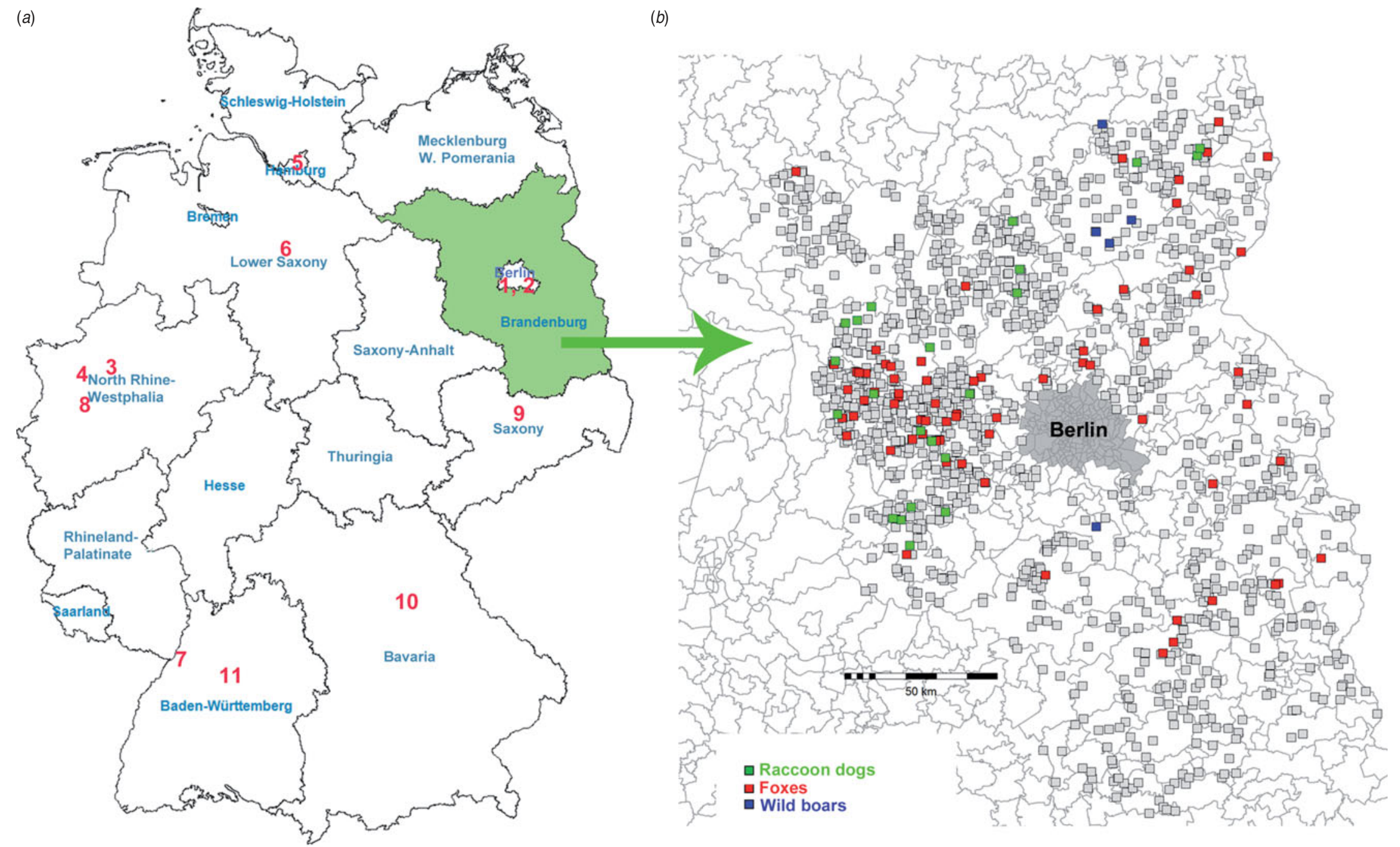

Fig. 1. (a) Sampling sites of captive animals in Germany (sample collection 1, red numbers indicate the sampling sites) and wild animals (serum collection 2 , green area). (b) Regional map of Brandenburg depicting sampling locations of wild animals. Coloured boxes indicate individuals that tested positive, grey boxes those that tested negative. Each box represents one individual; green, raccoon dogs; red, foxes; blue, wild boars. 
Table 1. Results of ELISA and Western blot for F. tularensis antibodies in different serum samples of zoo and wild animals

\begin{tabular}{lccc}
\hline \hline & $\begin{array}{l}\text { Animals tested, } \\
n(\% \text { of total) }\end{array}$ & $\begin{array}{l}\text { ELISA positive, } \\
n(\% \text { of group) }\end{array}$ & $\begin{array}{l}\text { Western blot } \\
\text { positive, } \\
n(\% \text { of group) }\end{array}$ \\
Species & & & \\
\hline Serum collection 1 (zoo animals) & $957(85 \%)$ & $32 *(3 \cdot 3 \%)$ & $2(0 \cdot 2 \%)$ \\
$\quad$ Zoo ungulates & $165(15 \%)$ & $9(5 \cdot 4 \%)$ & $1(0 \cdot 6 \%)$ \\
$\quad$ Other zoo species & $1122(100 \%)$ & $41(3 \cdot 7 \%)$ & $3(0 \cdot 3 \%)$ \\
$\quad$ Total $(n)$ & $928(69 \%)$ & $171(18 \cdot 4 \%)$ & $73(7 \cdot 9 \%)$ \\
Serum collection 2 (wild animals) & $345(25 \%)$ & $44(12 \cdot 8 \%)$ & $22(6 \cdot 4 \%)$ \\
$\quad$ Foxes (Vulpes vulpes) & $80(6 \%)$ & $6(7 \cdot 5 \%)$ & $6(7 \cdot 5 \%)$ \\
Raccoon dogs (Nyctereutes procyonoides) & $1353(100 \%)$ & $221(16 \cdot 3 \%)$ & $101(7 \cdot 4 \%)$ \\
$\quad$ Wild boars (Sus scrofa) & & & \\
$\quad$ Total $(n)$ & &
\end{tabular}

* Competitive ELISA.

were investigated and data were summarized by these three species groups (Table 1). Foxes and raccoon dogs were shot in Brandenburg between 2006 and 2009 for the monitoring of rabies within the framework of an official state monitoring programme and transported to the regional analytical authority. There, necropsies were conducted by a professional pathologist and blood was taken directly from the heart or from visceral cavities. Prior to shipment to the laboratory, samples were frozen at $-80{ }^{\circ} \mathrm{C}$ for 1 week to eliminate possible contamination with Echinococcus multilocularis eggs. Sera from wild boars were collected from 2005 to 2008 during classical swine fever monitoring, also within the framework of a state investigative programme. Serum or EDTA blood were taken by the hunters, sent to the laboratory and stored at $-20{ }^{\circ} \mathrm{C}$ until investigation. A vaccine against tularemia is not available and not applied in Germany for the animal population. Therefore, the presence of anti- $F$. tularensis LPS antibodies should be the result of a natural infection.

\section{Serological tests}

\section{Bacterial preparation, standard LPS ELISA and WB}

Preparation and inactivation of bacteria, LPS ELISA and WB were essentially done as described previously with minor modifications [17, 18]. For detection of antibodies against $F$. tularensis in animal sera (except zoo ungulates, see below), $50 \mu \mathrm{l} /$ well of protein G-horseradish peroxidase (HRP) conjugate (Millipore, USA) were used in a 1:500 dilution for ELISA and a 1:1000 dilution for WB. All ELISA-positive sera were confirmed by WB.

\section{Competitive ELISA}

The competitive ELISA was based on methods described previously and was used for the investigation of the zoo ungulates because of the unknown protein $\mathrm{G}$ binding capacity of the broad range of animal sera [19]. Briefly, flat-bottomed 96-well polystyrene plates (PolySorp, NUNC, Germany) were coated by passive absorption with $50 \mu \mathrm{l} /$ well LPS of $F$. tularensis (Micromun, Germany) at a concentration of $0.5 \mu \mathrm{g} / \mathrm{ml}$ in carbonate/bicarbonate buffer $(\mathrm{pH} 9.0$ ) for $1 \mathrm{~h}$ at $37^{\circ} \mathrm{C}$. Wells were washed three times with phosphate-buffered saline complemented with $0.05 \%$ Tween 20 (PBS-T), and $50 \mu 1$ serum diluted $1: 10$ were added in duplicate wells and incubated for $45 \mathrm{~min}$ at $37^{\circ} \mathrm{C}$. Fifty $\mu$ l of a highly specific monoclonal $F$. tularensis anti-LPS antibody, not cross-reacting with other bacteria [19, 20], conjugated to HRP (Seramun, Germany), were directly added without washing in an end-point concentration of $1 \mu \mathrm{g} / \mathrm{ml}$ per well and incubated at $37^{\circ} \mathrm{C}$ for $30 \mathrm{~min}$. After incubation wells were washed five times with $300 \mu$ l PBS-T. The wells were filled with $200 \mu \mathrm{l} o$-phenylendiamine (OPD; Sigma Aldrich, Germany) as substrate; reaction was stopped after $10 \mathrm{~min}$ by adding $50 \mu 1$ of $2.5 \mathrm{M}$ sulphuric acid. Optical density (OD) values were then recorded at $492 \mathrm{~nm}$ with a Sunrise Plate Reader (Tecan Instruments, Germany) interfaced with a computer. Results were expressed as percentage inhibition and were derived from the mean OD values for each sample by the following formula:

$$
\begin{aligned}
& \% \text { inhibition }= \\
& \frac{\text { OD sample }- \text { OD neg. control }}{\text { OD pos. control }- \text { OD neg. control }} \times 100 .
\end{aligned}
$$


Samples were considered as positive if they inhibited more than $45 \%$ [mean +3 standard deviation (s.D.)]. Only samples showing inhibition in competitive ELISA greater than $45 \%$ were confirmed by WB analyses. Samples with clear positive WB signal (LPS ladder) were stated as positive for $F$. tularensis antibodies.

\section{ELISA cut-off levels}

ELISA results below the mean blank from at least three independent experiments +1 S.D. calculated from the negative control sera were estimated as 'negative'. Results above the mean blank +3 s.D. were assumed to be 'positive', whereas all results between these two values were defined as 'borderline'. False-positive results in ELISA were avoided by confirming borderline and positive results in WB showing the presence of antibodies against the specific LPS ladder. The seroprevalence was calculated for individual animal groups by percentage of WB positively confirmed sera in relation to all sera of the serum collections of zoo or wild animals, respectively.

\section{RESULTS}

We tested a total of 1122 serum samples from captive animals of German zoos (collection 1, Fig. 1a, red numbers) and 1353 serum samples from wild animals from the area of the federal state of Brandenburg (serum collection 2, Fig. $1 a$, green area). The results are presented in Table 1. In collection 1, a total of 41 $(3 \cdot 7 \%)$ samples tested seropositive by competitive and/or indirect ELISA and three (0.3\%) of these sera were confirmed positive by WB, including one hippopotamus (Hippopotamus amphibius), one wisent (Bison bonasus) and one African wild ass (Equus africanus).

In collection 2 we detected $101(7 \cdot 4 \%)$ animals showing positive signals for the LPS of $F$. tularensis confirmed by WB (Table 1). The localization of the sampling sites and the serological results for all animals from collection 2 are shown in Figure $1 b$. Figure $2 a$ shows a confirmatory WB result of ELISApositive raccoon dogs and foxes. The typical LPS ladder is only present in positive samples, whereas negative samples show no signal.

As regards the seropositive hippopotamus, we were able to analyse consecutive serum samples throughout the years 2001, 2003, 2004 and 2006. In 2001 and 2003 they were negative; however, in 2004 and 2006 they were positive indicating a seroconversion during this period (Fig. 2b).

\section{DISCUSSION}

Historically, tularaemia in humans was spread throughout Germany with a relatively low incidence reported [10]. Some data indicating higher prevalence could be observed in the north-east and south-west of Germany. Over the last 10 years, from 2001 until November 2011, 119 human cases of tularaemia with 1-31 cases per year have been reported, most of them from the western parts of Germany [11]. During the last years, a tendency for an increase in the number of reported human cases has become apparent, but the real prevalence of tularaemia in Germany remains unknown. A cross-sectional serological study in Germany revealed that these numbers might be underestimated (seroprevalence $0 \cdot 2 \%$ ). A seroprevalence study investigating hunters (seroprevalence $1.7 \%$ ) showed an elevated risk of exposure to the tularaemia pathogen which was also underlined by a tularaemia outbreak in a group of hunters in 2006 $[17,18,20]$. In addition, outbreaks or single cases in wild animals, e.g. hares, and semi-free-living animals (marmosets and cynomolgus monkeys) have been described in Germany more recently [21-23].

Zoo animals could be at risk for $F$. tularensis infections because an oversupply of food can lead to a dense rodent population which could carry and transmit the pathogen. Usually, rodent control programmes reduce this risk, but tularaemia has been described in zoo animals previously [24-29]. Therefore, it was one aim of our study to conduct the seroprevalence study for tularaemia in different German zoos thereby obtaining further hints for possible sources of infection. Overall, we did not find any striking data on tularaemia seroprevalence using spot samples from zoo animals throughout Germany. The reasons for these negative results might be that we did not target the appropriate animal population (for this study we could only use pre-existing sera) or that zoos do not represent areas with an elevated risk of acquiring tularaemia. Interestingly, the single zoo animals which tested positive comprised a hippopotamus (H. amphibius), a wisent (B. bonasus) and an African wild ass (E. africanus). For ungulates, susceptibility to $F$. tularensis has been described before $[30,31]$, but these are the first cases reported in a hippopotamus or an equid. Additionally, we were able to show for the hippopotamus that the infection 

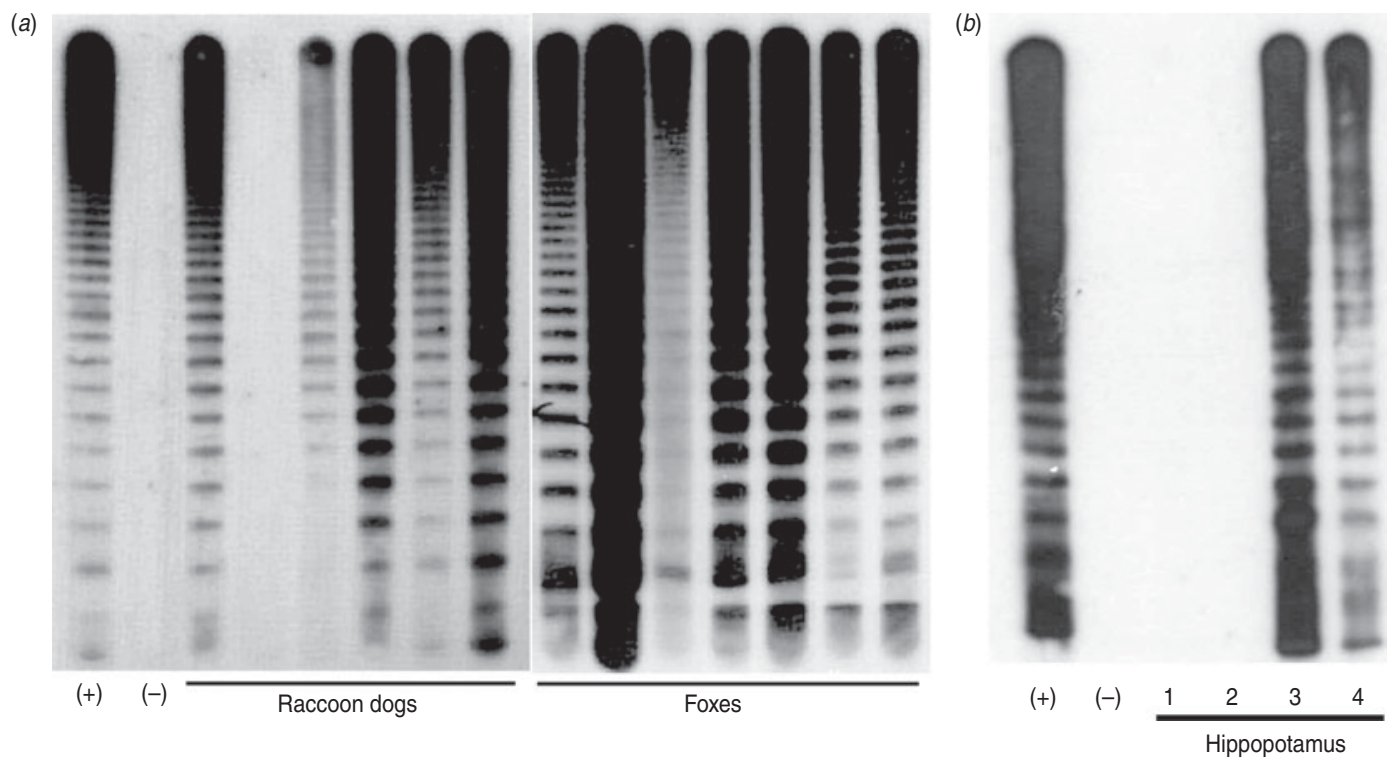

Fig. 2. Western blot for confirmation of ELISA samples tested positive. (a) Examples of positive samples of raccoon dogs and foxes from serum collection 2 showing the typical lipopolysaccharide (LPS) ladder. (b) Western blot with F. tularensis LPS extract showing sera of the hippopotamus that tested positive from serum collection 1 (zoo animals), depicting the seroconversion of the animal. Note the typical LPS ladder only in positive samples from 2004 and 2006. (+), Positive control; (-) negative control; raccoon dogs and foxes = serum collection 2 ; sera from hippopotamus (serum collection 1 ); 1, from 2001; , from 2003; 3, from 2004; 4, from 2006.

occurred on the premises of Berlin Zoo between the years 2003 and 2004, since the animal was tested negative in 2001 and 2003 and the indirect ELISA and WB for LPS antibodies of $F$. tularensis were both positive in 2004 and 2006. It can only be speculated on the source and mode of transmission of the tularemia agent in this case. Animals and humans could be infected by contaminated food or water. The source of F. tularensis could be carcasses or excrement of infected rodents which cannot be excluded in this case. This clearly shows the need for continuous rodent control programmes and also the investigation of suspicious deaths of rodents in confined environments.

The study area for wild animals encompassed the federal state of Brandenburg, surrounding the German capital Berlin and located in the north-east of Germany. Sixteen human cases of tularaemia were reported from this region between the years 2001 and 2011 [11] but almost nothing is known about the natural occurrence of $F$. tularensis in this area. In Mecklenburg-Western Pomerania, a northern neighbouring federal state, retrospectively a relatively high seroprevalence was found in hares $(10.7 \%)$ and a lower one in wild boars $(0.09 \%)$ in sera from the years 1976-1989 [32,33] as well as more recently in boars $(3 \cdot 1 \%$ in 1995/1996) [13]. To the south-west of
Brandenburg in Thuringia, F. tularensis has recently been isolated from a hare and in the western neighbouring state, Saxony-Anhalt, we reported a ticktransmitted human tularaemia [21, 34]. Therefore, the second aim of our study was to learn more about the activity of the tularaemia pathogen in Berlin and Brandenburg by a serological study of wild animals, also considering the above-mentioned positive results from a hippopotamus in Berlin Zoo. There are no ongoing rodent control programmes which could contribute to monitoring zoonoses in the natural environment. However, a state control programme was conducted from 2006 to 2009 to monitor rabies in wild animals in the region, including predators and omnivores. We took advantage of this programme to investigate specimens from predators and omnivores for the presence of antibodies against $F$. tularensis. We assumed that these animals might have a higher risk of becoming infected when consuming rodents. Rodents are highly susceptible to $F$. tularensis and often the source of infection in other mammals. In addition, wild animals are regularly infested with ticks, a known vector for $F$. tularensis [35-38]. Thus, 1353 serum samples of wild omnivores and predators from Brandenburg were investigated. Among foxes, raccoon dogs and wild boars we were able to show a seroprevalence of $F$. tularensis of $7 \cdot 5 \%$ on average, 
which indicates that tularaemia might be endemic in wild animals in Brandenburg. There appears to be a tendency that more positive samples could be found in the West of Berlin than in other regions of Brandenburg. This may coincide with two human cases reported from this region in 2011. In the same year, 17 human cases were reported from throughout Germany [11]. In addition, this is also consistent with a very recent observation in 2012 that $F$. tularensis could be confirmed as the cause of death of a beaver from this region [Landeslabor Berlin-Brandenburg, Frankfurt (Oder), Germany,unpublished data].

Our results also revealed that seroprevalence in these animals might serve as an indicator for enzootic tularaemia activity. These animals clearly develop a strong antibody titre against $F$. tularensis LPS after exposure to this pathogen. Clinical signs of tularaemia have not been observed in any of the examined animals. This is not surprising as an exposure to the pathogen need not be necessarily linked to a persisting infection or clinical disease. This is particularly true for the present study because we investigated animal species with a low sensitivity of contracting tularaemia $[2,5,39]$. In previous studies foxes were found to be seropositive for tularaemia with a high proportion, and carnivores together with wild boars are recognized as valuable sentinels in the detection of pathogens in wildlife populations and could serve as biological indicators [40, 41]. All three sentinel groups studied here have the potential to be used as indicators for the presence of the tularemia pathogen; however, we preferred foxes because the relative high number of sera was easy to obtain from within the framework of other investigations.

In addition to serological screening, organs like lung and liver from foxes and raccoon dogs were investigated by PCR and microbiological culturing in a parallel study, and $F$. tularensis spp. holarctica was isolated from the liver of one fox [42]. This isolation underlined the results of the serological screening and documented the presence of infectious $F$. tularensis in the study region.

In summary, it can be concluded that our approach allowed detection of the presence of the tularaemia pathogen in a region of Germany in which the occurrence of $F$. tularensis had not been suspected previously. This could contribute to explaining the incidence of single human cases in this area. However, the actual epidemiological situation and the determination of risk factors for human infections require further investigation. Additional isolates of
F. tularensis would underline the presence of the infectious pathogen; further attempts are in progress. Long-term surveillance of wildlife could help to identify areas with a higher risk of infection and also identify the natural reservoirs of $F$. tularensis in Germany. Although an invasion of wild animals into zoos can not be excluded, the transmission of tularaemia seems to be a rare event. The investigation of more various and highly susceptible animal species could provide further information on the exposure of zoo animals to the tularaemia pathogen.

\section{ACKNOWLEDGEMENTS}

The authors thank H. Ranisch for excellent technical assistance. This work was partly supported by a grant from the Federal Ministry of Education and Research (project no. 13N9601).

\section{DECLARATION OF INTEREST}

None.

\section{REFERENCES}

1. Dennis DT, et al., Working Group on Civilian Biodefense. Tularemia as a biological weapon: medical and public health management. Journal of the American Medical Association 2001; 285: 2763-2773.

2. WHO. WHO Guidelines on Tularemia. Geneva: WHO, 2007 (http://www.who.int/csr/resources/publications/ WHO_CDS_EPR_2007_7.pdf)

3. Tärnvik A, Priebe HS, Grunow R. Tularaemia in Europe: an epidemiological overview. Scandinavian Journal of Infectious Diseases 2004; 36: 350-355.

4. Champion MD, et al. Comparative genomic characterization of Francisella tularensis strains belonging to low and high virulence subspecies. PLoS Pathogens 2009; 5: e1000459.

5. Olsufiev NG, Dunayeva TN. Natural focality, epidemiology and prophylaxis of tularemia. Medicina 1970; 9: 11-18.

6. Ellis J, et al. Tularemia. Clinical Microbiology Reviews 2002; 15: 631-646.

7. Grunow R, et al. Differential diagnosis of tularaemia [in German]. Deutsche Medizinische Wochenschrift 2001; 126: 408-413.

8. Mörner T. The ecology of tularaemia. Revue Scientifique et Technique 1992; 11: 1123-1130.

9. Reintjes R, et al. Tularemia outbreak investigation in Kosovo: case control and environmental studies. Emerging Infectious Diseases 2002; 8: 69-73.

10. Anon. Tularaemia - prevalence in Germany [in German]. Epidemiologisches Bulletin 2007; 7: 51-56. 
11. Robert Koch-Institut. SurvStat@RKI (http://www3. rki.de/SurvStat/QueryForm.aspx).

12. Frölich K, et al. Epizootiologic and ecologic investigations of European brown hares (Lepus europaeus) in selected populations from Schleswig-Holstein, Germany. Journal of Wildlife Diseases 2003; 39: 751-761.

13. Al Dahouk S, et al. Seroprevalence of brucellosis, tularemia, and yersiniosis in wild boars (Sus scrofa) from north-eastern Germany. Journal of Veterinary Medicine, B: Infectious Diseases and Veterinary Public Health $2005 ; \mathbf{5 2 :}$ 444-455.

14. Aronova NV, Pavlovich NV. Comparative analysis of the immune response of a rabbit to antigens to live and killed Francisella species bacteria [in Russian]. Molekuliarnaia Genetika, Mikrobiologiia i Virusologiia 2001; 2: 26-30.

15. Grunow R, et al. Detection of Francisella tularensis in biological specimens using a capture enzyme-linked immunosorbent assay, an immunochromatographic handheld assay, and a PCR. Clinical and Diagnostic Laboratory Immunology 2000; 7: 86-90.

16. Probst C, Speck S, Hofer H. Serosurvey of zoo ungulates in central Europe. International Zoo Yearbook 2011; 45: 1-15.

17. Schmitt $\mathbf{P}$, et al. A novel screening ELISA and a confirmatory Western blot useful for diagnosis and epidemiological studies of tularemia. Epidemiology and Infection 2005; 133: 759-766.

18. Jenzora A, et al. Seroprevalence study of Francisella tularensis among hunters in Germany. FEMS Immunology and Medical Microbiology 2008; 53: 183189.

19. Greiser-Wilke I, Soine C, Moennig V. Monoclonal antibodies reacting specifically with Francisella sp. Zentralblatt für Veterinarmedizin, Reihe B 1989; 36: 593-600.

20. Hofstetter I, et al. Tularaemia outbreak in hare hunters in the Darmstadt-Dieburg district, Germany. Eurosurveillance 2006; 11 : E060119.3.

21. Müller W, et al. Detection of Francisella tularensis subsp. holarctica in a European brown hare (Lepus europaeus) in Thuringia, Germany. Veterinary Microbiology 2007; 123: 225-229.

22. Splettstoesser WD, et al. Re-emergence of Francisella tularensis in Germany: fatal tularaemia in a colony of semi-free-living marmosets (Callithrix jacchus). Epidemiology and Infection 2007; 135: 1256-1265.

23. Mätz-Rensing K, et al. Epizootic of tularemia in an outdoor housed group of cynomolgus monkeys (Macaca fascicularis). Veterinary Pathology 2007; 44: 327-334.

24. Hoelzle LE, et al. Tularaemia in a captive goldenheaded lion tamarin (Leontopithecus chrysomelas) in Switzerland. Veterinary Record 2004; 155: 60-61.

25. Posthaus $\mathbf{H}$, et al. Tularemia in a common marmoset (Callithrix jacchus) diagnosed by 16S rRNA sequencing. Veterinary Microbiology 1998; 61: 145-150.

26. Ketz-Riley CJ, et al. Tularemia type A in captive Bornean orangutans (Pongo pygmaeus pygmaeus). Journal of Zoo and Wildlife Medicine 2009; 40: 257-262.
27. Gyuranecz M, et al. Generalized tularemia in a vervet monkey (Chlorocebus aethiops) and a patas monkey (Erythrocebus patas) in a zoo. Journal of Veterinary Diagnostic Investigation 2009; 21 : 384-387.

28. Abril C, et al. Rapid diagnosis and quantification of Francisella tularensis in organs of naturally infected common squirrel monkeys (Saimiri sciureus). Veterinary Microbiology 2008; 127: 203-208.

29. Preiksaitis JK, et al. Human tularemia at an urban zoo. Canadian Medical Association Journal 1979; 121: 1097-1099.

30. Gordon JR, McLaughlin BG, Nutiuthai S. Tularaemia transmitted by ticks (Dermacentor andersoni) in Saskatchewan. Canadian Journal of Comparative Medicine 1983; 47: 408-411.

31. Hoberg EP, et al. Pathogens of domestic and freeranging ungulates: global climate change in temperate to boreal latitudes across North America. Revue Scientifique et Technique 2008; 27: 511-528.

32. Dedek J, et al. Results of epidemiological investigations for selected infectious diseases in hares [in German]. Monatshefte für Veterinärmedizin 1990; 45: 833-836.

33. Dedek $\mathbf{J}$, et al. Serological investigations for brucellosis and tularaemia in wild boars [in German]. Monatshefte für Veterinärmedizin 1986; 41: 150-153.

34. Lübbert C, et al. Prolonged course of tick-borne ulceroglandular tularemia in a 20 -year-old patient in Germany - case report and review of the literature [in German]. Deutsche medizinische Wochenschrift 2009; 134: 1405-1410.

35. Gyuranecz M, et al. Investigation of the ecology of Francisella tularensis during an inter-epizootic period. Vector-Borne and Zoonotic Diseases 2011; 11: 10311035.

36. Reese SM, et al. Transmission dynamics of Francisella tularensis subspecies and clades by nymphal Dermacentor variabilis (Acari: Ixodidae). American Journal of Tropical Medicine and Hygiene 2010; 83: 645-652.

37. Goethert HK, Telford SR 3rd. Quantum of infection of Francisella tularensis tularensis in host-seeking Dermacentor variabilis. Ticks and Tick-Borne Diseases 2010; 1: 66-68.

38. Hopla CE. The ecology of tularemia. Advances in Veterinary Science \& Comparative Medicine 1974; 18: 25-53.

39. Magnarelli L, Levy S, Koski R. Detection of antibodies to Francisella tularensis in cats. Research in Veterinary Science 2007; 82: 22-26.

40. McCue PM, O'Farrell TP. Serological survey for selected diseases in the endangered San Joaquin kit fox (Vulpes macrotis mutica). Journal of Wildlife Diseases 1988; 24: 274-281.

41. Hofer E. Natural reservoir for tularaemia and brucellosis. Biomed Austria 2007, Summer 16-17.

42. Nattermann $\mathbf{H}$, et al. First isolation of Francisella tularensis subspecies holarctica from foxes (Vulpes vulpes) in Germany 6th International Conference on Tularemia 2009, Berlin, 13-16 September 2009 (http:// www.tularemia-network.com/), P1 -43. 